\title{
Interventional Pain Management
}

\author{
Helen Gharaei* \\ Department of Anesthesiology and Pain Medicine, Boali Hospital, Emam-Hosaein Sq, Damavand St, Tehran, Iran
}

Received: September 29, 2014; Accepted: February 16, 2015, Published: February 25, 2015

*Corresponding author: Helen Gharaei, Department of Anesthesiology and Pain Medicine, Boali Hospital, Emam-Hosaein Sq, Damavand St, Tehran, Iran, Tel: +989198923151, Fax: +982166915196, E-mail: helengharaee@yahoo.com

\begin{abstract}
There are many approaches for managing the patient with chronic or acute pain: pharmacological, psychological, interventional, different medical, to call the foremost common. The field of interventional pain management methods including diagnosis and treatment of pain using various techniques such as nerve blocks, anesthetic or corticosteroid injection, intrathecal opioids, neurolysis, spinal cord stimulation and intrathecal pump. Knowing the way to perform a treatment strategy is additionally critically vital. In this article, clinical application of interventional pain management methods is briefly discussed. Interventional pain management methods treat refractory pain, reduce narcotic usage and improve life quality.
\end{abstract}

\section{Introduction}

There are many approaches for managing patient with chronic or acute pain: pharmacologic, psychological, interventional, different medical, to call the foremost common. All of those ways has its benefits and disadvantages. Knowing the way to perform a treatment strategy is additionally critically vital.

The field of interventional pain management methods including diagnosis and treatment of pain using various techniques such as nerve blocks, anesthetic or corticosteroid injection, intrathecal opioids, methods of destruction of nerve, such as assisted radiofrequency, nerve stimulation techniques such as spinal cord stimulation and intrathecal pump.

Interventional procedures for pain management have been developed as a new technique since 1960, its progress with the efforts of John J. Bonica in 1975. Steven Waldman first used this word in 1996. Professor Raj lifelong educational efforts have devoted his career for the education and training of Interventional pain specialists around the world. What was previously the role of anesthesiologists to do such procedures is now open to many other specialists (physical medicine and rehabilitation, neurologists, neurosurgeons, and so on). Imaging techniques have become a part of this new advance and are considered a good practice for interventional procedures in pain management. There are numerous developments in our ability to image the human body during interventional procedures. These include ultrasound, fluoroscopy, CT scanning [1-4].
The algorithmic approach to chronic pain is developed based on the best available evidence regarding the epidemiology of various identifiable sources of chronic pain and providing a stepby-step strategy for managing chronic pain patients based upon evidence-based guidelines.

The algorithmic approach to interventional pain management imply to use simple, low cost and less invasive procedure at first and then more invasive and high cost ones. Usually the first interventional procedure is a diagnostic and therapeutic block. Then, depending on the site of pain; neurolysis, radiofrequency, intradiscal procedure, intrathecal pump and spinal cord stimulation would be considered $[5,6]$.

\section{Nerve Block, Nerve Plexus Block, Ganglion Block}

Celiacplexus blockmanaged cancerpain of the gastrointestinal tract to the transverse colon, pancreas, stomach, gall bladder, adrenal mass, and the common bile duct. It is also effective for pain management of chronic pancreatitis and in acute intermittent porphyry. Splanchnic nerve block is used in pain management of retroperitoneal and flank and parallel cases mentioned in celiac block, however, because of the serious complications, it is used only if the celiac block is not effective Thoracic sympathetic chain blocks are effective in pain management of thoracic cancer (esophagus, bronchi, trachea, lungs), post- mastectomy phantom pain, shingles pain, upper limbs complex regional pain syndrome and profuse sweating of the hands that does not respond to usual treatments [7-9].

Hypogastria plexus block is used in cancer pain management of descending colon, sigmoid, rectum and bladder, prostate, prostatic urethra, seminal vesicles, testis, uterus, ovaries, vagina, and irritable bladder and intractable pelvic pain. Impair ganglion block is used in perineum pain management including: vulva, anus, distal of rectum, distal urethra and the lower third of the vagina. Stellate ganglion block control cancer pain of the head and neck, sympathetic pain of arm and hand, atypical facial pain and meniere's disease. Intercostals nerve block and nerve block of abdominal wall that cover the skin of the breast, control pain caused by shingles and cancer pain of chest, chest wall and abdominal wall (after the surgery and following breast removal or thoracotomy). Lumbar sympathetic chain blocks are indicated in controlling: post amputation pain, diabetic foot aches and 
vascular pains (Raynaud's phenomenon and disease, Buerger's disease), lower limbs profuse sweating, urogenital pain and in the lower limbs complex regional pain syndrome. Lumbar dorsal root ganglia block is effective in controlling sciatica [1-3,10-13]. Lumbar dorsal root ganglion block is also effective in controlling pain in amputated limbs [14,15].

Lumbar, thoracic and cervical Medial Branch Block (MBB) which block nerves that innervated facet joints, reduce pain in patients with chronic facetogenic low back pain, mid back pain and chronic neck pain or cervicogenic headache. Gasserian ganglion block is effective in controlling cluster headache and trigeminal neuralgia, persistent ear pain and facial pain caused by cancer or multiple sclerosis. Sphenopalatine ganglion block is indicated in migraine headache, atypical facial pain, ocular herpes, trigeminal neuralgia and sphenopalatine neuralgia. Occipital nerve block is useful in reducing migraine and tension headaches caused by neck problems and occipital neuralgia. Supraclavicular nerve blocks are effective in reducing shoulder pain. Sacroiliac joint blocks are effective in lumbar pain management [16-20].

\section{Neurolysis}

Radiofrequency neurolysis also called ablation, denervation, rhizotomy etc. It uses heat generated by radio waves to damage specific nerves and temporarily interfere with their ability to transmit pain signals.

Conventional radiofrequency or pulse radiofrequency could be used depending to the site of procedure. In dorsal root ganglion PRF is used to prevent permanent damage due to high temperature of CRF. Temperature in PRF is below 42, and therapeutic effect of electrical field managed pain. CRF is used in MBB and its therapeutic effect is superior to PRF in this region. In mixed nerves (e.g. sciatic, intercostals, femoral, median) PRF is used. Although PRF is not destructive but effect of high electrical field at the needle tip and hot flash may have destructive effect. So it is recommended to use sensory nerve stimulation at 0.5-0.7 and not put needle into the nerve, then applied PRF [21-23].

\section{Spinal Cord Stimulation}

Spinal Cord Stimulation (SCS) is a method of treatment in which a surgically implanted pulse generator sends electrical currents through the spine in order to interfere with nerve impulses that cause chronic pain. The pulse generator is inserted in the abdomen, and small, coated wires run to the point in the spinal canal where the pain originates. The pain is reduced because the electrical current interrupts the pain signal from reaching your brain. This method of treatment may be recommended for people who have Failed Back Surgery Syndrome (FBSS) or severe neurogenic pain caused by a degenerative spine condition. This method is also effective in neuropathic and ischemic pain $[3,12,24]$.

\section{Implantable Pumps}

Patients who are suffering from terminal illnesses like cancer and patients with intolerable pain, who cannot tolerate side effects of the higher-dose oral medications, are candidate for these pumps. This type of therapy is generally recommended for individuals with a life expectancy of greater than six months.

By implantable pumps, opioids and other approved medications, such as clonidine, Ziconotide, anesthetic drugs such as bupivacaine, tetracaine and ropivacaine pumped directly into the spinal cord.

Intrathecal pumps deliver small doses of medication directly to the spinal fluid. It consists of a small battery-powered, programmable pump that's deep-seated underneath the subcutaneous tissue of the abdomen and connected to a small catheter tunneled to the site of spinal entry. A pain pump may be a treatment option if all other traditional methods have failed to relieve symptoms [10,12].

\section{Kyphoplasty and Vertebroplasty}

vertebroplasty and kyphoplasty are similar medical spinal procedures in which bone cement is injected through a small hole in the skin into a fractured vertebra with the goal of relieving back pain caused by vertebral compression fractures, and is also sometimes performed for other conditions that may have led to a spinal fracture (e.g. tumor metastases to vertebral). Kyphoplasty is a variation of a vertebroplasty which attempts to restore the height and angle of kyphosis of a fractured vertebra. The procedure generally includes the employment of a small balloon that is inflated in the vertebral body to create a void within the bone prior to cement delivery. These techniques not only control pain, but also adjust vertebral high and prevent complication due to kyphosis. They are minimally invasive and are suitable in older patients with co morbidity $[3,25]$.

\section{The Intradiscal Methods}

The methods are used to control pain from herniated discs and sciatica pain. This technique is less invasive and a needle enters into the disc space from skin and relieves pressure inside the disc (nucleoplasty, decompressor) or can cause nerve neurotomy (radiofrequency, laser) or both.

In percutaneous disc nucleoplasty pulses of radio waves sends into the nucleus of a herniated disc. These radio waves vaporize little amounts of disc material, making associate empty area among the disc and the pressure on nerve roots or the spinal cord will disappear, providing immediate pain relief.

In dekompressor discectomy a small needle is advanced to the herniated disc guided by fluoroscope. A probe with a rotating tip is then inserted through the needle to achieve the ruptured intervertebral disc, once the probe is turned on, its tip drills away a part of the disc nucleus, making area for the ruptured intervertebral disc wall and relieving pressure on the nerve

Percutaneous intradiscal radiofrequency thermo coagulation is a procedure that allows the controlled delivery of heat to the intervertebral disc via an electrode or coil and coagulated disc.

Laser disc decompression has been used to deflate a disk somewhat. An optical fiber inserted into the disc by a needle. The heat created takes out a small amount of the middle of the disc. The warmth might cut back pain by moving the chemical structure within the disc [3,12]. 


\section{Caudal Neuroplasty}

Adhesions and scarring as epidural fibrosis may occur after spinal surgery that restricts the free movement of nerve roots, causing tethering and leading to pain. Caudal neuroplasty is introducing a catheter into the epidural space at caudal region. It has been shown to assist diminish scar formation, thereby decreasing the number of irritations on the spinal nerves

Today's the term of epidural adhesiolysis is used. This procedure is performed not solely in caudal regions of the spine, however additionally within the cervical, thoracic and lumbar regions. It has evolved over the years as an important treatment option for patients with intractable cervical, thoracic, and low back and leg pain too $[3,11]$.

\section{Ultrasound Guided Pain Management}

Interventional procedures in pain medicine are performed under fluoroscopy or CT guidance. US is used almost for every block which could be done under fluoroscopy or CT guidance. Some procedure like TAPB (Transverse Abdominal Plane Block), illioinguinal and iliohypogastric block, a rectus sheath block could be done only by the US [26]. Interventional block in thoracic region due to possibility of needle puncture of pleura is mostly done by the US.

US systems are more available and cheap these days. Transportable devices give high resolution and quality pictures. This device is available in almost every hospital. Potential advantages of ultrasound are: no hazard of radiation exposure, it could be done in every position, visualization of nerves and surrounding structures: vessels, muscles, bone and viscerapleura, lung, peritoneum, bowel, diagnostic recognizing anatomical variability and pathology real time image of needle, needle nerve contact and inject it spread, reduce complication: nerve injury, vessels puncture, pneumothorax etc., higher success rate, quicker onset, reduces performance time, reduce volume of local anesthetic [27-32].

\section{Conclusion}

Interventional pain management is an effective pain control method .Physicians must be familiar with its techniques and their application, as well as full assessment of painful cases. Using these methods at the appropriate time is very useful in controlling pain. These methods are useful in the management of persistent pain. And not only improves the quality of life but also helpful in reducing opioid use.

\section{References}

1. Waldman SD. Atlas of interventional pain management. 3rd ed, Philadelphia: Elsevier Health Sciences; 2009.

2. Waldman SD. Pain management. 1st ed, Philadelphia: Saunders Elsevier; 2007.

3. Prithvi RP, Leland L, Serdar E, Peter S, Waldman SD, Gabar R, et al. Interventional Pain Management: Image-Guided Procedures. 2nd ed, Philadelphia: Saunders; 2008.

4. Williams JE. Nerve blocks: Chemical and physical neurolytic agents. In: Sykes N, Bennett MI, Yuan CS. Clinical pain management: Cancer pain. 2nd ed. London: Hodder Arnold; 2008. p. 225-35.

5. Boswell MV, Trescot AM, Datta S, Schultz DM, Hansen HC, Abdi S, et al. Interventional techniques: evidence-based practice guidelines in the management of chronic spinal pain. Pain Physician. 2007; 10(1): 7-111.

6. Airaksinen O, Brox JI, Cedraschi C, Hildebrandt J, Klaber-Moffett J, F. Kovacs, et al. Chapter 4. European guidelines for the management of chronic nonspecific low back pain. Eur Spine J. 2006; 15 Suppl 2: S192-300. doi: 10.1007/s00586-006-1072-1.

7. Loukas M, Klaassen Z, Merbs W, Tubbs RS, Gielecki J, Zurada A. A review of the thoracic splanchnic nerves and celiac ganglia. Clin Anat. 2010; 23(5): 512-22. doi: 10.1002/ca.20964.

8. Krumova EK, Gussone C, Regeniter S, Westermann A, Zenz M, Maier C. Are sympathetic blocks useful for diagnostic purposes? Reg Anesth Pain Med. 2011; 36(6): 560-7. doi: 10.1097/AAP.0b013e318229bbee.

9. Ohseto K. Efficacy of thoracic sympathetic ganglion block and prediction of complications: clinical evaluation of the anterior paratracheal and posterior paravertebral approaches in 234 patients. J Anesth. 1992; 6(3): 316-31.

10. Atallah JN. Management of cancer pain. In: Vadivelu N, Urman RD, Hines RL. Essentials of pain management. New York: Springer; 2011. p. 597-628.

11. Daniel H. Kim, Kyung H. Kim and Yong C. Kim. Minimally invasive percutaneous spinal techniques .1st ed, Philadelphia: Saunders; 2010.

12. Cosgrove MA, Towns DK, Fanciullo GJ and Kaye AD. Interventional pain management. In: Vadivelu N, Urman RD, Hines RL. Essentials of pain management. New York: Springer; 2011. p. 237-299.

13. Gharaei H. Transforaminal epidural block. Anaesth Pain \& Intensive Care 2013; 17(3): 223-224.

14. Ramanavarapu V, Simopoulos TT. Pulsed radiofrequency of lumbar dorsal root ganglia for chronic post- amputation stump pain. Pain Physician 2008; 11(4): 561-6.

15. Imani F, GharaeiH, Rezvani M.Pulsed Radiofrequency of Lumbar Dorsal Root Ganglion for Chronic Postamputation Phantom Pain. Anesth Pain 2012; 1(3): 194-197. doi: 10.5812/kowsar.22287523.3768.

16. Manchikantil L, Singh V. Interventional Techniques in Chronic Spinal Pain. ASIPP Publishing, Kentucky; 2008.

17. Rathmell JP, Pino CA, Ahmed S. Spinal pain and the role of neural blockade. In: Cousins MJ, Carr DB, Horlocker TT, Bridenbaugh PO. Neural blockade in clinical anesthesia and pain medicine .4th ed, Philadelphia: Wolters Kluwer Health; 2009. 1063-1110.

18. Cousins MJ, Carr DB, Horlocker TT, Bridenbaugh PO. Neural blockade in clinical anesthesia and pain medicine 4th ed, Philadelphia: Wolters Kluwer Health.

19. Manchikanti L. Facet joint pain and the role of neural blockade in its management. Curr Rev Pain 1999; 3(5): 348-358.

20. Boswell MV, Colson JD, Sehgal N, Dunbar EE, Epter R. A systematic review of therapeutic facet joint interventions in chronic spinal pain. Pain Physician. 2007; 10(1): 229-53.

21. Gauci CA, Jankowiak B. Manual of RF techniques: a practical manual of radiofrequency procedures in chronic pain management. Meggen: FlivoPress; 2011.

22. Lou L, Gauci CA. Radiofrequency treatment in thoracic pain. Pain Pract. 2002; 2: 224-225. DOI: 10.1046/j.1533-2500.2002.02027.x. 
23. van Kleef M, Spaans F. The effects of producing a radiofrequency lesion adjacent to the dorsal root ganglion in patients with thoracic segmental pain by radiofrequency percutanious partial rhizotomy. Clin J Pain 1995; 11: 325-332.

24. Johnson MI, Oxberry SG, Robb K. Stimulation-induced analgesia. In Sykes N, Bennett MI and Yuan C-S. Clinical pain management: Cancer pain. 2nd ed. London: Hodder Arnold; 2008. p. 235-250.

25. Imani F, Gharaei H, Rezvani M. Management of Painful Vertebral Compression Fracture with Kyphoplasty in a sever cardio-respiratory compromise patient. Anesth Pain. 2012; 2(1): 42-45. doi: 10.5812/ aapm.5030.

26. Gharaei H, Imani F, Almasi F, Solimani M. The effect of ultrasoundguided TAPB on pain management after total abdominal hysterectomy. Korean J Pain. 2013: 26(4): 374-378. doi: 10.3344/kjp.2013.26.4.374.

27. Neal JM, Brull R, Chan VW, Grant SA, Horn JL, Liu SS, et al The ASRA evidence-based medicine assessment of ultrasoundguided regional anesthesia and pain medicine: Executive summary. Reg Anesth Pain Med. 2010; 35(2 Suppl): S1-9. doi: 10.1097/ AAP.0b013e3181d22fe0.
28. Narouze S. Ultrasound-guided interventional procedures in pain management. Evidence-based medicine. Reg Anesth Pain Med. 2010; 35(2): S55-S58. doi: 10.1097/AAP.0b013e3181d24658.

29. Peng PH, Narouse S. Ultrasound-guided interventional procedures in pain medicine: a review of anatomy, sonoanatomy and procedures. Part I: non-axial structures. Reg Anesth Pain Med. 2009; 34(5): 45874. doi: 10.1097/AAP.0b013e3181aea16f.

30. Antonakakis JG, Ting $\mathrm{PH}$, Sites B. Ultrasound-guided regional anesthesia for peripheral nerve blocks: an evidence-based outcome review. Anesthesiol Clin. 2011; 29(2): 179-91. doi: 10.1016/j. anclin.2011.04.008.

31. Abrahams MS, Horn JL, Noles LM, Aziz MF. Evidence-based medicine: ultrasound guidance for truncal blocks. Reg Anesth Pain Med 2010; 35(2 Suppl): S36-42. doi: 10.1097/AAP.0b013e3181d32841.

32. Bigeleisen PE. Ultrasound Guided Regional Anesthesia and Pain Medicine. 1st ed. London: Lippincott Williams \& Wilkins; 2009. p 9396. 